\title{
ALCANCE DE CLÁUSULAS DE SUMISIÓN MIXTAS PARA \\ LOS EFECTOS DE ACTOS DE COMPETENCIA DESLEAL EN REDES Y CONTRATOS DE DISTRIBUCIÓN EXCLUSIVA: COMENTARIO DEL AUTO DE LA AUDIENCIA PROVINCIAL DE ZARAGOZA N ${ }^{\circ} 728 / 2020$, SECCIÓN $5^{\mathrm{a}}$ "SÉ LO QUE HICISTEIS EL ÚLTIMO ACUERDO"
}

\author{
SCOPE OF HYBRID CHOICE OF COURTS AGREEMENTS \\ AND CROSS BORDER UNFAIR COMPETITION ACTS WITHIN \\ EXCLUSIVE DISTRIBUTION AGREEMENTS AND NETWORKS: \\ COMMENTS ON THE ZARAGOZA PROVINCIAL COURT \\ RULING (DIVISION 5TH) Nº728/2020 \\ "I KNOW YOU DID LAST AGREEMENT"
}

\author{
Dra. Anna María Ruiz Martín \\ Lecturer in Law-Research Fellow \\ Genova Business School-Universitat Oberta de Catalunya
}

Recibido: 14.06.2021 / Aceptado: 14.07.2021

DOI: https://doi.org/10.20318/cdt.2021.6305

\begin{abstract}
Resumen: El asunto que se comenta en este análisis suscita interés para los litigios de competencia desleal y los contratos de distribución con pacto de exclusiva y elemento extranjero. En este procedimiento del Auto y otros anteriores que hubo entre las partes, se dilucidaba si una cláusula de sumisión expresa mixta que estaba inserta en el contrato de distribución, tenía alcance sobre los presuntos actos de competencia desleal cometidos por una de las partes de este contrato, que había sido resuelto en un primer procedimiento, ante los mismos tribunales. La Audiencia Provincial de Zaragoza entendió en el segundo procedimiento que en el alcance de la cláusula de sumisión expresa mixta no se podían ver entendidos los actos de competencia desleal demandados. Primero, porque considera que la redacción de la cláusula no tenía tanto alcance, y porque los actos de competencia desleal no tienen cabida en el ámbito material de la Convención de la Haya de 2005. Segundo, porque los efectos de estos actos desleales se habían producido o desplegado en el mercado norteamericano. Entendiendo que como la cláusula de sumisión expresa no era válida para otorgarles competencia judicial internacional en este caso, se debía aplicar el foro de competencia territorial del artículo 52.1.12 de la LEC, para actos de competencia desleal, que tampoco les otorgaba competencia para conocerlos.

Palabras clave: sumisión expresa, cláusulas mixtas, competencia desleal, B2B, contratos de distribución, pactos de exclusiva, responsabilidad contractual, extracontractual, alcance de las cláusulas, Convención de la Haya de 2005, LOPJ, LEC, competencia territorial, Bruselas I bis.
\end{abstract}

\footnotetext{
Abstract: The case law of this analysis is of special relevance for the cross-border claims of unfair competition and exclusive distribution contracts. The interest relies on certain claims wherein the Courts must assess the scope of a choice of court agreement previously settled in the contract between the parties, i.e.: whether this choice of court agreement will encompass also unfair competition acts among the
} 
professionals. This ruling of Zaragoza Provincial Court rendered that according to the material scope of the Hague Convention on choice of court agreements of 2005, unfair competition is excluded and therefore, the alleged acts of unfair competition by which the claimant filed the lawsuit before the Spanish courts could not be considered included in the scope of the choice of court agreement of this exclusive distribution contract. Besides, the Court uphold that in this case the effects of the act of unfair competition affected the American market but not the Spanish market when applying the forum for tort liability and the territorial jurisdiction rule of the Spanish Civil Procedure Act.

Keywords: choice of court agreements, hybrid clauses, unfair competition, $B 2 B$, distribution contracts, exclusive agreements, contractual liability, tort, Hague Convention of 2005, LOPJ, Brussels I bis Reg, LEC

Sumario: I. Los litigios de competencia desleal transfronteriza y sus particularidades; II. Cuestiones de competencia judicial internacional; 1. El supuesto de hecho y el Auto de la AP de Zaragoza: dos procedimientos y una cláusula de sumisión mixta o gris; 2. De la Haya a Bruselas haciendo escala en Zaragoza: el instrumento jurídico adecuado para determinar la validez de la cláusula de sumisión expresa en el caso de Autos; 3 . El ámbito material y espacial de la Convención de la Haya de acuerdos de elección de foro; 4. Particularidades de los contratos de distribución con pacto de exclusiva: ¿cláusula de no competencia ex post contracto?; III. Aspectos de la competencia territorial en materia de competencia desleal transfronteriza en el Derecho procesal español: 1. Alternativa en el supuesto de hecho para valorar la competencia judicial internacional de los tribunales españoles; 2 . Disonancias cognitivas: la solución de la norma de competencia territorial en materia de competencia desleal y la solución de la norma de competencia judicial internacional; IV. Conclusiones.

\section{Los litigios de competencia desleal transfronteriza y sus particularidades}

1. Pocas veces se dilucidan litigios transfronterizos relativos a la disciplina de la competencia desleal que envuelvan a su vez, la interpretación del alcance de las cláusulas de sumisión expresa a los actos/prácticas de competencia desleal nacidos de una relación comercial previa que las partes tenían mediante contrato. Aunque no sea habitual y los actos de competencia desleal desde las normas del Derecho internacional privado se califican de forma clásica como responsabilidad de tipo extracontractual (tort-economic tort), siendo contravenciones a los deberes de conducta en los mercados, nada impide que puedan tener consideración de obligación nacida de un deber contractual accesorio al contrato $\mathrm{u}$ obligación contractual, más que de un "contrato" per $s e^{1}$. Deberes de tipo contractual que las mismas normas del Derecho sustantivo de la competencia desleal reconoce para algunos ilícitos concurrenciales de tipo desleal ${ }^{2}$.

2. También es cierto que los actos de competencia desleal nunca han sido excluidos del alcance de las cláusulas de sumisión expresa. Las partes en determinado tipo de contratos puede atribuir el conocimiento de estos actos en la redacción de las cláusulas de sumisión expresa que incluyan entre el

\footnotetext{
${ }^{1}$ Cuestión diferente es su caracterización en las normas del DIPr europeo y español en el foro especial de la obligación extracontractual, en cuanto pueda haber un solapamiento de deberes en la relación comercial que no esté claro a la hora de calificar el ilícito concurrencial desleal tal como el TJUE ha establecido en su jurisprudencia y que da lugar a otros problemas diferentes de los problemas que se pueden presentar a la hora de aplicar el foro de la sumisión expresa. Como ejemplo de esta complejidad, STJUE as. Brogsitter, C-548/12, de 13 de marzo de 2014 (ECLI:EU:C:2014:218); algunos comentarios en la doctrina de interés, S. SÁNCHEZ LORENZO "La delimitation entre matière contractuelle et matière délictuelle dans l'espace judiciare européen: a propos de l'affaire Brogsitter", JDI Clunet, vol. 4, 2016,pp. 471-478; A. Dickinson, "Towards an agreement on the concept of "contract" in EU private internacional law", Lloyd's Maritime and Commercial Law Quarterly, 2014,pp. 466-474; M.A. Cebrí́n SALVAT, "Estrategia procesal y litigación internacional en la Unión Europea: Distinción entre materia contractual y extracontractual", $C D T$, vol. 6, no 2, 2014, pp. 315-329.

2 En el Derecho español de la Competencia desleal, por ejemplo, el artículo 14 de la Ley 3/1991, de 10 de enero, de competencia desleal, $B O E, \mathrm{n}^{\circ} 10$, de 11 de enero de 1991.
} 
clausulado. En particular, en contratos como en el que las partes en el procedimiento habían pactado. Contratos del tipo Business to Business (B2B), de relaciones comerciales entre profesionales ${ }^{3}$.

3. Antes de analizar el Auto y procedimientos relacionados se hacen las siguientes reflexiones en esta Introducción, que pueden arrojar luz sobre supuestos de bastante complejidad en el ámbito de los litigios transfronterizos de la competencia desleal y las particularidades que la merecen, como es el presente supuesto de hecho. Reflexiones en torno a los aspectos generales compartidos para todos los litigios en materia civil y mercantil y, en torno a los aspectos particulares de la vertiente procesal internacional de la competencia desleal.

4. En primer lugar, es necesario diferenciar entre el tipo de actos o prácticas comerciales desleales que los tribunales deben conocer. En su evolución jurídica, de ilícito de responsabilidad extracontractual (tort) a ilícito de mercado, la normativa de la competencia desleal diferencia claramente los distintos intereses tutelados en la normativa actual ${ }^{4}$. Evolución acogida en la jurisprudencia del Tribunal de Justicia de la Unión Europea en su interpretación de las normas de DIPr europeo a estos litigios ${ }^{5}$.

De forma actual, la normativa de la competencia desleal ya no sólo tutela los intereses de los particulares en el mercado, sino que junto con el Derecho antitrust o de la libre competencia, tutela otros intereses de mayor relevancia, como es el orden público económico del mercado (o mercados). Primer límite añadido a la autonomía de la voluntad de los operadores jurídicos privados en los mercados. Ambos cuerpos jurídicos lo hacen, pero desde diferente posición en lo que se conoce como su aplicación pública (public enforcement) y su aplicación privada (private enforcement) ${ }^{6}$. Con ello, esta disciplina que siempre se ha solapado con otros cuerpos jurídicos, ahora se solapa con otros cuantos más que tutelan las relaciones privadas y públicas del mercado. Para evitar estos solapamientos, el análisis detallado de la función de cada cuerpo jurídico es necesario por los tribunales. Mucho más en particular en litigios transfronterizos donde la complejidad se incrementa a la hora de caracterizar el objeto de la demanda para aplicar los foros adecuados en sede de competencia judicial internacional y para aplicar la correcta ley en sede de ley aplicable?

5. En el Auto que se analiza y procedimientos relacionados, estos actos de competencia desleal que se alegaban por una de las partes son de los considerados por la normativa de la competencia desleal,

3 Vid., A. Espiniella MenÉndeZ, « Competencia judicial internacional respecto de actos desleales con los competidores", $C D T$, vol. $10, \mathrm{n}^{\circ} 2$, pp. 276-305, pp. 279-281. Incluso recordando que la materia de la competencia desleal siempre se ha podido ver entendida en el alcance de cláusulas de sumisión a arbitraje..

${ }^{4}$ Inter alia, J. M. Bischoff, "La concurrence déloyale en droit international privé", Trav.com.fr.dr.int.pr., 1972, pp.53-79; A. Dyer, "Unfair Competition in Private International Law", $R$. des C., t. IV, Martinus Nijhoff Publishers, vol. 211, 1988, pp. 381-443; N. Pires de Carvlaho "Current Trends in the Multilateral Evolution of Unfair Competition Law", en J. De Werra (ED.) et al, Défis du droit de la concurrence déloyale. Challenges of Unfair Competition Law, Schulthess, pp. 1-29; C. KESsedjian, “Competition”, en C. Mclachlan \& P. Nygh (eds.), Transnational Tort Litigation: Jurisdictional Principles, Oxford University Press, 1996, pp. 171-189

5 Vid. J. BASEDOw, "The Law of Open Societies: private ordering and public regulation of International Relations", Rec. des C., t. 264, Martinus Nifhoff, 2013, at 9-516; M. Danov, "Global Competition Law Framework: A Private International Law Solution Needed", Journal of Private International Law, vol. 12, nº1, 2016, at 77-115; B. VILÁ CostA, "How to Apply Articles 5(1) and 5(3) Brussels I Regulation to Private Enforcement of Competition Laws: a Coherent Approach", en J. BASEDOw, S. FrancQ \& L. IDOT, International Antitrust Litigation, Hart Publishing, 2012, pp.17-39; M.Danov \& F.BeCKer, "Governance Aspects of Cross-Border EU Competition Law Actions", JPIL, Vol. 10, n³, 2014, pp. 359-401; M. Danov, F. Becker \& P. Beaumont, Cross Border Antitrust EU Competition Law Actions, Hart, 2013; A.L. Calvo Caravaca \& J. Carrascosa GonzÁLEZ, "El Derecho internacional privado de la Unión Europea frente a las acciones por daños anticompetitivos", CDT, Vol. 10, n², 2018, pp. 7-178; C. Otero García CASTRILlón, "El alcance extraterritorial del Derecho de la competencia y su utilización como medida comercial. La perspectiva estadounidense, comunitaria y española", GJUEyC, n 212, 2001, pp. 34-56.

${ }^{6} \mathrm{H}$. Muir WatT, "La fonction économique du droit international privé", Revue Internationale de Droit Économique, Vol 1, 2010, at 103-122 ; ID., "Aspects économiques du Droit international privé (Réflexions sur l'impact de la globalisation économique sur les fondements des Conflits de lois et de Jurisdictions)", Rec. Des C., t. 307, Leiden/Boston, Martinus Nijhoff Publishers, 2005, pp. 39-365 ; J. Carrascosa GonzÁlez, "Règle de conflit et théorie économique", Revue critique de Droit International Privé, Vol. 101, nº3, 2012, pp. 521-538.

7 A-L. Calvo Caravaca \& J. Carrascosa González, Derecho Internacional Privado, vol. I, $16^{\text {a }}$ ed., Comares, 2016, esp. pp. $169-173$. 
del tipo Business to Business (en adelante, $B 2 B$ ). Aquellos actos que se considera que sólo perjudican los intereses (económicos) de los otros competidores en el mercado. No excluyendo la posibilidad que afecten también a los intereses económicos de los consumidores (ilícitos concurrenciales de tipo desleal Business to consumer-B2C), y los del mercado en general ${ }^{8}$.

6. Sin embargo, en estos litigios sólo se dilucidan si los actos comerciales desleales han afectado principalmente los intereses económicos de los profesionales o competidores en el mercado/s. Están además muy relacionados y sometidos por los límites del Derecho de contratos y los derechos de exclusiva, como era el caso. Con estas características que los "encasillan" en la parte más privada del Derecho de la competencia desleal sin tener la misma incidencia en el orden público económico (los intereses económicos generales), la norma los diferencia de los otros, con otro tipo de consecuencias jurídicas 9 .

7. Desde las normas del Derecho sustantivo, se ha comentado en el párrafo anterior que existen ciertos contratos $B 2 B$ que se encuentran afectados por límites que el Derecho contractual, el Derecho de la libre competencia y el Derecho de la competencia desleal, e incluso del Derecho de las propiedades inmateriales (intelectual e industrial). Con ello, se limita el ejercicio de la autonomía de la voluntad, por razones de orden público económico, especialmente desde el ámbito del Derecho de la competencia que los tribunales también deben tener en consideración a la hora de prejuzgar estos actos ${ }^{10}$. Considerando que dichos actos pueden haber nacido de una relación contractual que limitaba a las partes su ejercicio del derecho a competir en el mercado bien, mediante determinadas cláusulas como son los pactos de no competencia durante y ex post contractuales o non disclosure agreements (NDAs), como la no revelación de secretos comerciales (tutela del know-how) ${ }^{11}$.

8. En segundo lugar, después de un análisis de los aspectos particulares se podrá aplicar de forma correcta la norma adecuada a cada uno de estos litigios. Por ejemplo, desde las normas del DIPr, para saber si el Acuerdo de la Haya de 2005 para los acuerdos de elección de foro ${ }^{12}$, entiende incluidos

\footnotetext{
${ }^{8}$ El modelo actual es el denominado "modelo social" en el que se reconocen tutelados por la norma, los tres intereses económicos del mercado: de los competidores $(B 2 B)$, de los consumidores $(B 2 C)$ y del mercado en sí mismo, el orden público económico; A. Menéndez Menéndez, La competencia desleal, Civitas, 1988; J. Massaguer Fuentes, Comentario a la ley de competencia desleal, Civitas, 1999: M. VIRGós SorIANo, El Comercio internacional en el nuevo derecho español de la competencia desleal (Un análisis del art. 4 de la Ley española de Competencia Desleal de 1991), Civitas (Estudios de Derecho mercantil), 1992, que ya explica con el promulgamiento de la Ley de competencia desleal española en 1991, que pasa a convertirse en un cuerpo de normas que ordenan las relaciones de mercado; J.I. Ruiz Peris, "Panorámica de la reforma en materia de Competencia desleal", en J.A. Gómez Segade, A. García Vidal, M. Olivencia RuIz (EDs.), El nuevo derecho mercantil en el umbral del s. XXI: libro homenaje al Prof. Dr. Carlos Fernández-Novoa con motivo de su octogésimo cumpleaños, Marcial-Pons, 2010, pp. 379-390; R. HiLty, "The Law Against Unfair Competition and Its Interfaces", en R. HiLty \& F. Henning-Bodewig (eds.), Law Against Unfair Competition: Towards a New Paradigm in Europe?, MPI Studies on Intellectual Property, Competition and Tax Law, ${ }^{\circ} 1$, Springer, pp. 1-53.

${ }^{9}$ Desde el DIPr europeo puede observarse dichas diferencias atendiendo a la redacción del artículo 6 del Reglamento Roma II que distingue en sus apartados $1^{\circ}$ y $2^{\circ}$ (Considerando 21), entre los ilícitos concurrenciales desleales $B 2 C$ y $B 2 B$ en materia de ley aplicable; Reglamento Roma II, Reglamento (CE) No864/2007 del Parlamento Europeo y del Consejo de 11 de julio de 2007 relativo a la ley aplicable a las obligaciones extracontractuales ("Roma II"), DOUE, L 199/40, de 31 de julio de 2007; J. GLÖCKNER, "Unfair Trading Practices in the Supply Chain, Disparities in Bargaining Power in European Contract, Competition and Unfair Competition Law or: Law, Economics and System in the "New Legal Order", GRUR Int., vol. 12, 2016, pp. 1106-1121; A. BEATER, Unlauterer Wettbewerb; Unlauterer Wettbewerb aus verschiedenen Perspektiven, Mohr Siebeck, 2011; en relación a como se entienden las cláusulas de sumisión expresa de forma diferenciada en el ámbito de las practices comerciales desleales $B 2 C$, STJUE as. Henkel, C-167/00, 1 de octubre de 2002 (ECLI:EU:C:2002:555). Los intereses que se tutelan que emanan del Derecho privado institucional, del Derecho europeo de consumo conllevan una tutela especial diferenciada en las relaciones comerciales $B 2 B$.

${ }^{10}$ P. A. De Miguel Asensio, "Capítulo II.- Bienes inmateriales, Derecho de la competencia y responsabilidad extracontractual”, en J.C. Fernández Rozas, R. Arenas García \& P. A. De Miguel Asensio (eds.), Derecho de los negocios internacionales, $4^{\mathrm{a} e d}$., Iustel, 2013, pp.145-156; ID. "The Private International Law of Intellectual Property and of Unfair Commercial practices: Convergence or Divergence?”, S. LeiBle \& A. OHLY (eds.), Intellectual Property and Private International Law, Mohr Siebeck, 2009, pp. 137-190.

${ }^{11}$ Como ejemplo, P. A. De Miguel Asensio, Contratos internacionales sobre propiedad industrial, $2^{\mathrm{a}}$ ed, Civitas, 2000 ; A. Font Segura, La protección internacional del secreto empresarial, t.XXX, Eurolex, 1999.

${ }_{12}$ Convenio de 30 de junio de 2005 sobre Acuerdos de Elección de Foro, de 1 de octubre de 2005, en vigor desde el 1 de octubre de 2015, disponible en: https:/www.hcch.net/es/instruments/conventions/full-text/?cid=98
} 
los actos nacidos de la competencia desleal o no en su ámbito material, para determinar la validez de las cláusulas de elección de foro insertadas en los contratos entre las partes. Y si la cláusula de sumisión expresa es válida según esta Convención o bajo otra norma, como puede ser el Reglamento Bruselas I bis.

El Auto, al margen de estos problemas procesales de tipo civil internacional, también interesa por el tratamiento que se hace sobre la norma especial de competencia territorial para litigios de competencia desleal, en concreto del artículo 52.1.12 ${ }^{\mathrm{a}}$ Ley de Enjuiciamiento Civil $\left(\mathrm{LEC}^{13}\right)$. Se considera que hubiera merecido mucho más razonamiento jurídico por parte de los juzgadores, sobre todo del criterio de los efectos, en contraposición con la solución que se ofrece en sede de competencia judicial internacional para los litigios de competencia desleal transfronteriza, tanto en el DIPr europeo como en el español.

9. En relación a los aspectos generales y dado que lo que se ponía en tela de juicio por las partes en la declinatoria, era la validez y alcance de una cláusula de sumisión expresa se hacen también estas consideraciones previas. Las cláusulas de elección de foro o sumisión expresa no tienen un ámbito limitado a la responsabilidad contractual, o aquella nacida del contrato entre las partes. Si las partes en su libertad para negociar deciden también otorgar competencia a los tribunales de un Estado en particular para conocer de actos de competencia desleal, este aspecto debe ser apreciado y tenido en cuenta por estos tribunales ${ }^{14}$.

Esto es así en lo que la Doctrina, por ejemplo, Calvo Caravaca y Carrascosa Gónzalez, ha explicado sobre la independencia de la cláusula de sumisión expresa. Siendo un "contrato" o "acuerdo" dentro del mismo contrato. Con autonomía propia. Basado en el principio de separabilidad (severability principle $)^{15}$.

De esta forma, y aunque estén incluidas en un contrato, se atenderá a la letra de la cláusula para conocer el alcance la misma, y a su validez, conociendo finalmente sobre qué actos que pueden haber nacido fuera de la obligación contractual, las partes decidieron someterlos a determinada autoridad judicial o no. Respetando de esta forma, la voluntad de las partes en el contrato (su autonomía de la voluntad) querida por el legislador para este foro ${ }^{16}$. Se añade que la independencia de la cláusula de sumisión expresa es de tanto alcance que, aún declarando la nulidad de un contrato, su validez puede sobrevivir al mismo.

\section{Cuestiones de competencia judicial internacional}

\section{El "supuesto de hecho" y el Auto de la AP Zaragoza : dos procedimientos y una cláusula de sumisión mixta o gris}

10. Del Auto principal que se analiza que resolvía un recurso de apelación por una declinatoria internacional interpuesta por la empresa demandada considerando la falta de competencia judicial internacional de los tribunales de Zaragoza, se desprende que, entre las partes en apelación, recurrente (empresa española) y recurrido (empresa norteamericana), existía un contrato. En dicho contrato, las

13 Ley 1/2000, de 7 de enero, de Enjuiciamiento Civil, $B O E \mathrm{n}^{\mathrm{0}} 7$, de 8 de enero de 2001.

14 De hecho, en la jurisprudencia del TJUE en relación con las cláusulas de elección de foro y acuerdo de distribución selectiva, STJUE as. Apple Sales International c. MJA y otros, C-595/17, de 24 de octubre de 2018, (ECLI:EU:C:2018:854); STJUE as. Cartel Damage Claims (CDC), C-352/13, de 21 de mayo 2015 (ECLI:EU:C:2015:335).

15 A-L. Calvo Caravaca \& J. Carrascosa González, Derecho Internacional Privado..op.cit., esp. pp. 268-270; un análisis exhaustivo del foro de las cláusulas de sumisión expresa en el Reglamento Bruselas I bis, A. RoDRíGUEz BENOT, "Sección 7a . Prórroga de la competencia”, en P. Blanco-Morales Limones, F.F. Garau Sobrino et al., (Coord.), Comentario al Reglamento (UE) $N^{\circ} 1215 / 2012$ relativo a la competencia judicial, el reconocimiento y la ejecución de resoluciones judiciales en materia civil y mercantil (Reglamento Bruselas I refundido), Aranzadi, 2016, pp. 545-580; de forma exhaustiva y desde el Derecho comparado, M. Ahmed, The Nature and Enforcement of Choice of Court Agreements: A Comparative Study, Bloomsbury, 2017.

16 Desde el Informe P. Jenard sobre la Convención de Bruselas de 1968, "Report Mr P Jenard on the Convention of 27 September 1968 on jurisdiction and recognition and enforcement," DOCE, C 59, 5 March 1979, Vol. 22 at C 59/37; A. RoDRíGUEZ Benot, "Sección 7a. Prórroga de la competencia" en, P. Blanco-Morales Limones, F.F. Garau Sobrino et al., (Coord.), Comentario al Reglamento (UE) $N^{\circ} 1215 / 2012$ relativo a la competencia judicial, el reconocimiento y la ejecución de resoluciones judiciales en materia civil y mercantil (Reglamento Bruselas I refundido), Aranzadi, 2016, pp. 545-580. 
partes habían incluido una cláusula de sumisión expresa mixta a los tribunales de Zaragoza y a la Cámara de Comercio International (CCI) teniendo por tanto como alternativa a la jurisdicción ordinaria para resolver las controversias, el arbitraje comercial internacional de tipo institucional ${ }^{17}$.

11. En primera instancia la empresa norteamericana interpuso declinatoria internacional alegando la falta de competencia judicial internacional de los juzgados de Zaragoza para conocer de los presuntos actos de competencia desleal, que la empresa española le acusaba haber cometido en territorio español ${ }^{18}$. El juzgador de instancia aceptó la declinatoria internacional planteada por la empresa norteamericana y la empresa española recurrió en apelación ante la Audiencia Provincial de Zaragoza (en adelante, AP de Zaragoza), considerando que la cláusula de sumisión expresa era válida en el caso de autos, dado que se podían ver incluidos en su redacción y alcance los actos de competencia desleal. La AP de Zaragoza apreció como el juzgador de instancia que la cláusula de sumisión expresa no era válida para conocer de estos actos. Añadiendo en su fallo que dicho contrato había sido ya resuelto en otro procedimiento anterior entre las partes ${ }^{19}$. Esto es, era la segunda vez que la empresa española demandaba a la empresa norteamericana ante los tribunales españoles.

12. La primera vez, en el año 2017 , la empresa española solicitaba resolver ante los tribunales de instancia de Zaragoza, el contrato de distribución internacional con pacto de exclusiva, que existía entre ambas partes desde el año $2010^{20}$. Tanto el Juzgado de Zaragoza de Primera Instancia n ${ }^{\circ} 20$ como la AP de Zaragoza conocieron del procedimiento a favor de la empresa española, entendiendo la validez del acuerdo de sumisión tanto a los tribunales de Zaragoza como a la Corte arbitral de la CCI. Al ser una cláusula de sumisión mixta tenía validez tanto en sede judicial como arbitral ${ }^{21}$. No pudiendo considerarla una cláusula de sumisión expresa asimétrica en cuanto ambas partes habían negociado la cláusula en igualdad de condiciones sin ser ninguna de ellas, de forma unilateral, la que estableció ambas sumisiones. O al menos, así se desprende de la lectura de la Sentencia de la AP de Zaragoza del primer procedimiento (2017). En este primer procedimiento la SAP de Zaragoza si reconoce el incumplimiento contractual, especialmente del pacto de exclusiva entre la empresa española y la empresa norteamericana.

13. Volviendo al segundo procedimiento del año 2020 y en base a lo anterior, la Audiencia Provincial de Zaragoza resuelve y ratifica el auto de instancia, considerando como ya se ha explicado, que para los actos de competencia desleal demandados en este segundo procedimiento, la cláusula de sumisión expresa de dicho contrato resuelto en el año 2017, no atribuía la competencia judicial internacional a los tribunales españoles.

Además, según el AAP in fine, estos actos se habían producido o desplegado sus efectos en el mercado norteamericano, que no el español ${ }^{22}$. Añade que como los actos de competencia desleal no se

17 Estas cláusulas están permitidas por el artículo 25 del Reglamento Bruselas I bis siendo aceptadas por la jurisprudencia española, A-L., Calvo Caravaca \& J. Carrascosa GonzÁlez, Derecho Internacional ..., op.cit. vol.1, p. 263; Sobre la noción de arbitraje institucional, también controvertida, J. C. FERnÁNDEZ RozAS, "Luces y sombras del arbitraje institucional en los litigios transfronterizos", Revista de la Corte española de arbitraje, vol. XXIII, 2008, pp. 71-104, G.F.CABALLERo, "El arbitraje institucional", en V. DE CARVAhlo Leal \& A. Uscanga BARRAdas, El derecho y sus razones: aportaciones de jóvenes investigadores, Bubok, 2013, pp. 221-227; Z.S. TANG, Jurisdiction and Arbitration Agreements in Internacional Commercial Law, Routlegde, 2014.

${ }^{18}$ En base al artículo 63 y ss. de la LEC.

19 Sentencia $n^{\circ}$ 00844/2017, de la Audiencia Provincial de Zaragoza, Sección 2a de 28 de diciembre de 2017, SAP Z 2813/2017 (ECLI:ES:APZ:2017:2813), AH 1º $1^{\circ}$.

${ }^{20}$ Sentencia $n^{\circ} 00844 / 2017$, de la Audiencia Provincial de Zaragoza, Sección $2^{\text {a }}$, de 28 de diciembre de 2017, SAP Z 2813/2017 (ECLI:ES:APZ:2017:2813), FD 5º

${ }^{21}$ Se reproduce el contenido de la cláusula de sumisión mixta: FD 1: "En su artículo 19, tras señalarse que cualquiera de las partes tendrá derecho a recurrir a las disposiciones del Reglamento del Procedimiento Precautorio Arbitral (Paris) y declararse ambas sujetas a ese Reglamento se dice que, "todo litigio, controversia o reclamación resultante de este contrato o relativo al mismo, incluyendo en particular su incumplimiento, interpretación, ejecución, resolución o nulidad, se resolverá mediante arbitraje de derecho, definitivamente, de acuerdo con el Reglamento de Arbitraje de la Cámara de Comercio Internacional por uno o más árbitros nombrados conforme a dicho Reglamento de Arbitraje". Seguidamente dice en su artículo 21: "las partes por medio del presente documento se someten de forma irrevocable expresa a los procesos, jurisdicción y Juzgados de Zaragoza".

${ }^{22}$ AAP n $^{\circ}$ 68/2020, Sección 5a, FD 5. 
encuentran incluidos en el ámbito material del Acuerdo de la Haya sobre acuerdos de elección de foro del 2005, y según nuestras normas de competencia territorial en materia de competencia desleal (artículo 52.1.12 ${ }^{\mathrm{a}} \mathrm{LEC}$ ), los tribunales españoles no son los competentes ni internacional ni territorialmente.

14. La SAP de Zaragoza del primer procedimiento dedica de forma más exhausta a analizar la validez o no de esta cláusula de sumisión expresa mixta. Con una redacción que puede decirse amplia si se atiende a que las partes incluyen en la misma "todo litigio, controversia o reclamación resultante de este contrato o relativo al mismo" 23 . Aunque esta redacción incluye en la cláusula de sumisión expresa el arbitraje institucional de la CCI, puesto que en la de sumisión a jurisdicción ordinaria la redacción es más laxa ${ }^{24}$, es de relevancia para entender si finalmente dicha cláusula si hubiese tenido el alcance necesario para conocer de los actos de competencia desleal tras la ruptura del contrato de distribución con pacto de exclusiva entre las partes.

\section{De La Haya a Bruselas haciendo escala en Zaragoza: el instrumento jurídico adecuado para determinar la validez de la cláusula de sumisión expresa en el caso de Autos}

15. Como se conoce bien, si en un contrato internacional o con elemento extranjero existe una cláusula de sumisión expresa, de acuerdo con la jerarquía de foros establecida en los instrumentos de Competencia judicial internacional para asuntos-materias civil y/o mercantil, el foro adecuado para conocer de las controversias es el foro de la sumisión expresa. De modo que si la cláusula de sumisión expresa no demuestra ser inválida, a la luz del análisis requerido de su validez formal y material, se debe respetar tanto por los tribunales elegidos (prorrogatio fori) como por los que no han sido elegidos por las partes (derogatio fori) ${ }^{25}$.

De hecho, con estos acuerdos también se puede excluir por las partes, la aplicación del foro general del domicilio del demandado y los foros especiales por razón de la materia de la obligación contractual y de la extracontractual ${ }^{26}$.

16. Para litigios en los que se atribuye la competencia a los tribunales de cualquier de los Estados miembros, el artículo 25 del Reglamento Bruselas I bis, es el foro y el instrumento jurídico que se deberá aplicar. El artículo ya no hace diferencia, -como hacía el anterior Reglamento Bruselas I (Reg. 44/2001) y que el Convenio de Lugano 2007 mantiene en su redacción-, en que al menos una de las dos partes debe tener el domicilio en un Estado miembro ${ }^{27}$.

Lo determinante para activar este foro del Reglamento Bruselas I bis, es que se haya atribuido competencia judicial internacional a los tribunales de un Estado miembro, con independencia del domicilio de las partes contratantes. Si bien es sabido que todos estos instrumentos precitados excluyen de su ámbito material el conocimiento del arbitraje $\mathrm{e}^{28}$, si existe sumisión a un tribunal arbitral en estas cláusulas

${ }^{23}$ A.Rodríguez Benot, "Sección 7 $7^{\text {a }}$ Prórroga de la ...”, loc.cit, en Comentario al Reglamento (UE) Nº 1215/2012 relativo a la competencia judicial, el reconocimiento y la ejecución de resoluciones judiciales en materia ..., op.cit., pp. 563-564; en la jurisprudencia del TJUE, por ejemplo, STJUE as. Powell Duffryn, C-214/89, de 10 de marzo de 1992 (ECLI:EU:C:1992:115), limitando que todo litigio tenga causa en determinadas relaciones jurídicas entre las partes.

${ }^{24}$ Nota a pié de página 21.

25 Esto es conocido como el "doble efecto" de las cláusulas de sumisión expresa.

26 STJUE as. Cartel Damage Claims (CDC), C-352/13, de 21 de mayo 2015 (ECLI:EU:C:2015:335), par 59 y ss.; C. WADLOW, "Bugs, spies and paparazzi: jurisdiction over actions for breach of confidence in private international law", EIPR, vol. 30, nº, 2008, pp. 269-279, p.279; A. Rodríguez Benot, "Sección 7ª Prórroga de ...", loc.cit. Comentario al Reglamento (UE) $N^{\circ} 1215 / 2012$ relativo a la competencia judicial, el reconocimiento y la ejecución de resoluciones judiciales en materia civil...op.cit., p. 560; J. SUDEROW, “Acciones derivadas de los ilícitos antitrust: el foro especial de la obligación extracontractual después de la sentencia CDC Hydrogen Peroxide", CDT, Vol, 8, n², 2018, pp. 306-329.

${ }^{27}$ Convenio relativo a la competencia judicial y a la ejecución de resoluciones judiciales en materia civil y mercantil, hecho en Lugano el 30 de octubre de 2007, DOCE L 339, de 21 de diciembre de 2007 (viz. Artículo 23).

${ }^{28} \mathrm{Cfr}$. artículo 1 apartado $2^{\circ}$ letra e, del Reglamento Bruselas I bis (Considerando 12); no obstante, esta afirmación exige ciertas matizaciones que no son objeto del comentario, v.gr., A-L., Calvo Caravaca \& J. Carrascosa González, Derecho In- 
mixtas, los tribunales de los Estados miembros deben valorar y podrán apreciar cuales son las controversias que las partes quisieron someter a la jurisdicción ordinaria o al arbitraje (de forma incidental ${ }^{29}$.

De nuevo, atendiendo a la redacción de la cláusula, para conocer su alcance a obligaciones que pueden nacer como consecuencia de la relación comercial entre las partes, incluyendo aquellas que no se consideran o califican como contractuales ${ }^{30}$.

17. En el caso de Autos, especialmente del primer procedimiento entre ambas empresas, es donde los tribunales de Zaragoza valoraron la redacción de dicha cláusula mixta, como ya se ha explicado. La competencia se atribuyó a los tribunales de Zaragoza (España) un Estado miembro. Para el caso de determinar la competencia judicial internacional de los tribunales españoles y a la luz de este análisis, se entiende que hubiese sido de aplicación el artículo 25 del Reglamento Bruselas I bis.

18. Este hecho desplaza la aplicación del artículo 22 bis Ley Orgánica del Poder Judicial (LOPJ) sobre acuerdos de jurisdicción ${ }^{31}$, dado que no se atribuía a tribunales de terceros Estados la competencia para conocer de ninguna de las controversias. Si la redacción de la cláusula, por ejemplo, hubiese otorgado la misma competencia a los tribunales norteamericanos que a los españoles.

19. El artículo 22 bis LOPJ, como norma atributiva y no distributiva (a diferencia de las contenidas en el Reglamento Bruselas I bis y otros Convenios internacionales de competencia judicial internacional), sólo le hubiese ayudado a los tribunales españoles para determinar si la cláusula de sumisión expresa a los tribunales norteamericanos no siendo "exclusiva", hubiera podido otorgarles la competencia judicial internacional también a ellos. Si la cláusula atribuyere de forma inequívoca y exclusiva la competencia judicial internacional a los tribunales norteamericanos, entonces los tribunales españoles, en virtud de la redacción de los foros de la norma española, deben declinar su competencia a favor de los mismos.

\section{El ámbito material y espacial de la Convención de la Haya de 2005 sobre acuerdos de elección de foro}

20. Ahora bien, y dado que se menciona en el Auto, cabe considerar si el Acuerdo de la Haya del 2005 sobre elección de foro hubiera sido de aplicación en el caso de autos. Cuando se redactó el artículo 25 del Reglamento Bruselas I bis, ya se había redactado y negociado la Convención de la Haya de acuerdos de elección de foro. Aunque no entró en vigor para los Estados miembros hasta el año 2015.

Es bien sabido que el Reglamento Bruselas I bis no impide la aplicación de otros Convenios internacionales que estén en vigor para los Estados miembros y otros terceros Estados en las materias que abarca. Al contrario, la cláusula de compatibilidad que el mismo Reglamento Bruselas I bis contiene, hace posible una coexistencia coherente entre todos estos instrumentos jurídicos ${ }^{32}$.

ternacional..., op.cit., vol. 1, pp. 216-217; J. C. FeRnÁNDEZ RozAs, "El Reglamento Bruselas I revisado y el arbitraje: crónica de un desencuentro", La Ley Unión Europea, vol. I, n9, 2013, pp.5-23; M. GómEZ JENE, “Arbitraje international y Reglamento Bruselas I bis", Revista de arbitraje comercial y de inversiones, vol. VIII, nº 1, 2015, pp. 15-48.

${ }^{29}$ Ibid.

30 Vid., A. Espiniella MenÉndez, « Competencia judicial internacional...”, loc.cit,, p.281 citando el caso Top Aiways vs. Thai airways, en donde también se debatía si los actos de competencia desleal en una red de contratos de agencia y distribución tenían cabida en la cláusula de sumisión a arbitraje, SAP n ${ }^{\circ}$ 8878/2017, Audiencia Provincial de Barcelona, Sección $15^{\text {a }}, 20$ de octubre de 2017 (ECLI: ES:APB:2017:8878), FD $1^{\circ}$ pto 4: “(...) la juez a quo señala que la cláusula de sometimiento a arbitraje alcanza únicamente a la acción por incumplimiento del contrato de agencia. No afecta, por el contrario, a la acción vinculada al contrato de distribución y a la de la competencia desleal".

${ }^{31}$ Ley Orgánica 6/1985, de 1 de julio, del Poder Judicial, modificada por Ley Orgánica 7/2015, de 21 de julio, BOE, nº 174, de 22 de julio de 2015, artículo 22 bis LOPJ: "En aquellas materias en que una norma expresamente lo permita, los Tribunales españoles serán competentes cuando las partes, con independencia de su domicilio, se hayan sometido expresa o tácitamente a ellos (...)".

${ }^{32}$ Artículo 71 Reglamento Bruselas I bis; el Informe explicativo de la Convención de la Haya del 2005, también en su página 795 (35) aclara la compatibilidad entre ambos instrumentos jurídicos: M.DogauchI \& T.C. HARTLEY, "Rapport explicatif annexé à 
21. En acuerdos de sumisión expresa, si se cumplen los siguientes requisitos que se exponen a continuación, la Convención de la Haya del 2005 desplazará la aplicación del Reglamento Bruselas I bis. Los requisitos son: que las partes pertenezcan a un Estado parte del Convenio habiendo atribuido de forma inequívoca la competencia judicial internacional a los tribunales de estos Estados parte (primer requisito-ámbito territorial/espacial) en que el Convenio se encuentre en vigor (segundo requisitoámbito temporal). Y el tercer requisito es que la materia de la que verse el contrato y que la cláusula de sumisión expresa alcance, se encuentre entendida dentro del ámbito material de la precitada Convención (ámbito material).

22. En el AAP de la Sección $5^{a}$ (2019) se hace mención que el Convenio de la Haya podría haber sido de aplicación en defecto del artículo 25 Bruselas I bis, pero que no se puede aplicar porque el acto por el que se ha demandado es un acto de competencia desleal excluido de la Convención, de su ámbito material ${ }^{33}$.

23. Dos consideraciones sobre esta afirmación.

- Primera.- Estados Unidos sólo consta que ha firmado el Convenio (2009), pero no que lo haya ratificado sin estar aún en vigor para este Estado. Según la Convención de Viena de 1969 sobre Derecho de los tratados ${ }^{34}$, por los que los tratados internacionales se rigen para regular sus formalidades, un tratado que no ha sido aún ratificado, aunque haya sido firmado, no significa que esté en vigor y despliegue plenos efectos para el Estado firmante y sus nacionales (a no ser que se haya acordado lo contrario) ${ }^{35}$. Esto ya lo excluye para ser aplicado en este caso, incluso si la cláusula de sumisión expresa se hubiera considerado válida o con suficiente alcance para entender de los actos de competencia desleal por los tribunales españoles.

- Segunda.- Los actos de competencia desleal son confundidos por la AP de Zaragoza, con los actos o obstáculos a la libre competencia mencionados en el artículo 2 apartado 2 letra h. Sobre este particular, el análisis es meritorio. El informe explicativo "Informe DogauchiHartley" sobre la Convención lo aclara ${ }^{36}$. Las cláusulas de elección de foro pueden extender su campo de aplicación y por tanto su alcance, a las obligaciones extracontractuales nacidas de un acto comercial desleal. Si de esta manera lo han acordado las partes. Lo que la Convención de la Haya de 2005 sobre acuerdos de elección de foro establece en el art.2.2.h, es que no se aplicará a los actos nacidos como consecuencia del incumplimiento del Derecho antitrust o de libre competencia, pero no hace referencia expresa a la competencia desleal. No excluye de su ámbito material estos actos o prácticas comerciales desleales ${ }^{37}$.

la Convention du 30 juin 2005 sur les accords d'election de for", Conférence de La Haya de Droit international privé, 2013, pp. 1-104, disponible la versión electrónica en : https://assets.hcch.net/docs/0de60e2f-e002-408e-98a7-5638e1ebac65.pdf

${ }_{33}$ Se reproduce el FD 4 del AAP de Zaragoza, Sección 5a: "En principio, podría ser aplicable el Convenio de la Haya de 30 de junio de 2005, por cuento ha sido suscrito por los Estados Unidos de América y España. Sin embargo, el artículo 2.2. establece : «El presente Convenio no se aplicará a las siguientes materias: $h$ ) los obstáculos de la competencia” (la cursiva no es del texto original).

${ }_{34}$ Instrumento de adhesión de 2 de mayo de 1972, del Convenio de Viena sobre el Derecho de los Tratados, adoptado en Viena el 23 de mayo de 1969, $B O E \mathrm{n}^{\circ} 142$, de 13 de junio de 1980.

35 Vid. J. D. González Campos, L.I. Sánchez Rodríguez y P. A. Sáenz de Santa María, Curso de Derecho internacional público, Civitas, $7^{\mathrm{a} e d,}$ 2002, esp. pp. 215-220., considerando la dimensión individual o particular de la entrada en vigor de los tratados, para cada uno de los Estados que han negociado el tratado, de acuerdo a la Convención de Viena de 1969; De forma actual son parte de esta Convención, los EEMM de la UE, México, Montenegro y Singapur.

36 M.Dogauchi \& T.C. Hartley, "Rapport explicatif annexé à la Convention du 30 juin 2005 sur les accords d'election de for", Conférence de La Haya de Droit international privé, 2013, pp. 1-104, disponible la versión electrónica en : https://assets. hcch.net/docs/0de60e2f-e002-408e-98a7-5638e1ebac65.pdf

${ }^{37}$ En la versión inglesa: Article 2 para 2 (h): anti-trust (competition) matters; versión francesa: "les entraves à la concurrence". 
24. El punto 60 del Informe de Dogauchi-Hartley explica que los actos producidos como obstáculos al Derecho antitrust expresamente excluidos del ámbito material, se refiere los actos de los artículos 101 y 102 del TFUE ${ }^{38}$. Esto es, lo que se conoce y se ha mencionado en la introducción como la aplicación pública del Derecho antitrust. Sin embargo, no está incluyendo lo que se conoce cómo competencia desleal ${ }^{39}$.

25. Ad abundantiam, en el punto 63 del mismo Informe Dogauchi-Hartley se matiza que no es que no se incluyan tampoco los actos nacidos de la infracción del Derecho antitrust. Si se podrán ver incluidos en su ámbito material cuando sean como consecuencia de una ruptura contractual, esto es, que hayan nacido del contrato o que tengan relación con una relación comercial que las partes tenían con anterioridad. De nuevo, de un contrato que suele tener límites impuestos por el Derecho de la libre competencia como son los contratos de distribución ${ }^{40}$. Los actos de Derecho antitrust que se excluyen de la Convención son los que se dilucidan cómo objeto principal de la demanda, pero no cuando el contrato es nulo como consecuencia de la infracción de un deber del Derecho antitrust $t^{41}$. Como, por ejemplo, puede ser la infracción del pacto de exclusiva y / o de cláusulas de no competencia entre otros ${ }^{42}$. Algo que se ha conocido como la "teoría de las restricciones accesorias" en el ámbito del Derecho antitrust, en este tipo de contratos (y que puede ser extrapolable a determinados actos/ilícitos concurrenciales de competencia desleal $B 2 B)^{43}$.

\section{Particularidades de los contratos de distribución con pacto de exclusiva: ¿cláusula de no com- petencia ex post contrato?}

26. Al hilo de lo anterior, entre las partes existía un contrato de distribución con pacto de exclusiva. Aunque este aspecto no era el discutido, si que se analiza por la posibilidad que hubiera existido una cláusula o pacto de no competencia post contractual entre las partes. Y para saber si los actos de competencia desleal se hubieran visto incluidos en el alcance de la cláusula de sumisión mixta como consecuencia de la contravención de dichos deberes y/u obligaciones de tipo contractual en una relación comercial previa, requisito sine qua non para entender que la redacción los comprende ${ }^{44}$. Es cierto que la AP de Zaragoza tiene razón en considerar, que el contrato fue resuelto en el procedimiento

38 Tratado de Funcionamiento de la Unión Europea, hecho en Lisboa el 13 de diciembre de 200 (versión consolidada), $B O E$ n 286 de 27 de noviembre de 2009.

${ }^{39}$ Cfr. M.Dogauchi \& T.C. Hartley, "Rapport explicatif annexé à la Convention du 30 juin 2005 sur les accords d'election de for... », loc.cit., p. 803 (43), pto. 60 : « (...) Sub-paragraph h does not cover what is sometimes called " unfair competition»" (in French, concurrence déloyale), for example, misleading advertising or passing one's goods off as those of a competitor". En la nota a pié de página 88 del Informe se clarifica que la versión francesa "les entraves à la concurrence" no se refieren en ningún caso a los actos de competencia desleal.

${ }^{40}$ L. Berenguer Fuster, "Derecho de la Competencia y Contratos de Distribución", Círculo de Derecho Administrativo, 2010, pp. 225-242; M.Pérez Pereira, "Contratos de distribución: entre teoría y realidad", en Estudios sobre el futuro Código mercantil: libro homenaje al profesor Rafael Illescas, ed. Universidad Carlos III de Madrid, 2015, pp. 1651-1666.

${ }^{41}$ Ibid., ptos. 62-63. "On the other hand, if a person sues someone under a contract, and the defendant claims that the contract is void because it infringes anti-trust/competition law, the proceedings are not outside the scope of the Convention, since antitrust / competition matters are not the object/subject of the proceedings but arise merely as a preliminary question (...)"; B. Rodger, EU Competition Law and Private International Law: a developing relationship, Handbook on European Competition Law, Elgar Original Reference, 2013, pp. 456-490; P. CARO DE SousA, "Should Jurisdiction Clauses Be Interpreted Differently in Competition Law Cases?: A comment on Case C-595/17 Apple", Competition Policy International (CPI) EU News, 2018, disponible en: https://www.competitionpolicyinternational.com/wp-content/uploads/2018/11/EU-News-Column-November2018-2-Full.pdf ; J. Suderow \& A.L. Calvo Caravaca, "Aplicabilidad de un acuerdo de elección de foro a una reclamación de indemnización de daños por vulneración del artículo 102 TFUE: El caso Apple Sales International (C-595/17)”, CDT, vol. 11, n², 2019, pp. 439-451.

42 Ibid., p. 867 (47). Pto, 76. Intellectual property contracts; en la Jurisprudencia del TJUE, STJUE as. Coty Germany, C-230/16, 6 de diciembre de 2017 (ECLI:EU:C:2017:941).

${ }^{43}$ L. Miranda Serrano, "Restricciones accesorias y prácticas colusorias", $D N$, vol. 11, no 122, 2000, pp. 1-50; J. Martí Miravalls, "Las restricciones accesorias, necesarias y proporcionadas en el contrato de Franquicia", 2009, pp. 1-26.

${ }^{44}$ A. Espiniella MenÉndez, « Competencia judicial internacional...”, loc.cit,,p.304. 
anterior. Pero la cláusula no se limitaba en su redacción a las obligaciones de tipo contractual, según el análisis realizado.

27. No obstante, se puede hacer dos apuntes, basados en la presunción que se realiza y a falta de otros datos ofrecidos por las resoluciones del primer y segundo procedimiento.

Primero: la cláusula de sumisión expresa puede subsistir aún cuando un contrato sea nulo o resuelto. Cómo se mencionó en la Introducción, esto es debido al "principio de separabilidad" del resto de cláusulas. En relación al análisis que debe realizarse de estas cláusulas de su validez formal y material tal como establece el artículo 25 del Reglamento Bruselas I bis. Siendo este el artículo e instrumento jurídico que hubiera debido aplicarse en este caso. Y aunque es cierto que son accesorias al contrato, habrá que determinar si por la ley de los tribunales que las partes eligieron (lex fori prorrogatio), dicha cláusula podría subsistir incluso tras disuelto el contrato entre las partes ${ }^{45}$, que les siguiera otorgando competencia judicial internacional a los tribunales elegidos en la misma, de estos deberes u obligaciones de tipo contractual.

28. Segundo: pudiera ser que dichos actos de competencia desleal nacieron de forma posterior como consecuencia de las relaciones profesionales con otros competidores de la propia red de distribución internacional entre la empresa española y la norteamericana. Nada se dice si existía alguna cláusula o pacto de no competencia entre ambas, que fuera el detonante de este segundo procedimiento basado en presuntos actos de competencia desleal. No siendo algo ajeno a este tipo de contratos y redes comerciales, como se ha puesto de relieve.

29. De hecho, estas cláusulas o pactos de no competencia post contractuales son típicas y controvertidas en dichos contratos. Si bien, cuando se han incluido en el contrato, limitan la competencia por un tiempo determinado con compensación económica, para los contratantes en redes de distribución, agencia, franquiciados o contratos de licencias sobre derechos de propiedad intelectual de forma post contractual.

Límite dado en estos contratos por el Derecho de la libre competencia por su repercusión en la competencia, atendiendo a la ley material que pueda regir el contrato ${ }^{46}$. Y lo más importante para estos litigios, que despliegan su eficacia cuando el contrato termina durante el tiempo pactado por las partes.

30. El hecho que se hubiera mencionado en el Auto o en el primer procedimiento entre las partes, hubiera sido valioso para valorar si aún resuelto el contrato, esta cláusula impedía a la empresa norteamericana demandada durante un tiempo limitado competir en el mismo mercado con los competidores u otros profesionales / clientes de la red de distribución. O si hubiera existido una infracción del deber de compensación por clientela, traspaso del know how a otros profesionales, etc ${ }^{47}$. Actos que también desde el Derecho de la competencia desleal se observan como ilícitos concurrenciales desleales.

45 A-L., Calvo Caravaca \& J. Carrascosa González, Derecho Internacional..., op.cit., vol. 1, p. 270; también consagrado en la jurisprudencia del TJUE desde la STJUE as. Benincasa, C-265/95 de 3 de julio de 1997 (ECLI:EU:C:1997:337).

${ }^{46}$ Desde la óptica ius privatista, A-L, Calvo Caravaca \& J. Carrascosa González, Derecho Internacional Privado, vol. II, 16 ed., Comares, 2016, esp. pp. 976-978; J. MASEDA Rodríguez, Aspectos internacionales de la concesión mercantil(De Conflictus Legum. Estudios de Derecho internacional privado), Universidad Santiago de Compostela, 2000; A. EsPINIELLA MenÉndez, El contrato de distribución comercial internacional, Thomson Aranzadi, 2018; M.A. Domínguez García, "Los contratos de distribución: agencia y concesión comercial", en A.L.Calvo Caravaca \& L. Fernández de la Gándara (COORD.), Contratos internacionales, Tecnos, 1997, pp. 1275-1383; en el ámbito del Derecho sustantivo, L. J. GIRARD, "Responsabilidad del concedente de contratos de distribución por invasiones producidas en zonas otorgadas en exclusividad", Revista argentina de Derecho empresario, 2007, disponible online en: http://estudiocaselli.com.ar/img/publicaciones/2007_08_RevistaArgentinadeDerechoEmpresario02.pdf ; M. J. GonZÁlez-Orús Charro, La extinción de los contratos de distribución comercial, Universidad de Salamanca publicaciones, 2015, disponible en: https://pdfs.semanticscholar.org/0d57/7d72c02a552bcbbda99f 3ab17ce3735a9e76.pdf.

47 M.Pérez Pereira, "Contratos de distribución: entre ...", loc.cit., en Estudios sobre el futuro Código mercantil: libro homenaje al profesor..., pp. 1661-1662. 
Pero es cierto que no como infracciones de tipo contractual, sino como la jurisprudencia española viene desarrollando como contravenciones a los deberes generales de conducta en el mercado ${ }^{48}$. Incluso han llegado a no considerarse actos de competencia desleal en algunos supuestos ${ }^{49}$.

También hubiese servido para valorar dónde se produjeron de forma potencial, los efectos de dichos actos de competencia desleal que la empresa española demandaba (límite dado en estas relaciones comerciales por el Derecho de la competencia desleal). En qué mercado, o mercados, como lugares determinados. No descartando la posibilidad que, en redes de este tipo, los mercados afectados y / o relevantes pueden ser varios, y no limitados a un solo territorio. Datos que hubiesen sido de particular interés para observar todos estos problemas de tipo procesal y sustantivo en el litigio y valorar la aplicación de un foro u otro, atendiendo a la validez o invalidez de la cláusula de sumisión expresa.

31. Lo único que se observa en la lectura de la SAP (2017) es que el tribunal en el primer procedimiento conoció de diversas infracciones de tipo contractual, considerada la más grave por la AP, la infracción del pacto de exclusiva en cuanto la empresa norteamericana había permitido el plagio de los productos que tenían contratados ambas empresas en su red de distribución exclusiva. Sin embargo, durante la duración del contrato entre las partes.

\section{Aspectos de la competencia territorial en litigios de competencia desleal transfronteriza en el Derecho procesal civil español}

\section{Alternativa en el supuesto de hecho para valorar la falta de Competencia judicial internacional de los tribunales españoles}

32. El AAP (2020) considera en el FD2 ${ }^{\circ}$ y el FD $5^{\circ}$ que según el artículo 52.1.12 LEC donde el legislador español determina la competencia territorial para litigios de competencia desleal (al margen de las normas de competencia judicial internacional) no se puede entender que los actos demandados hayan producidos efectos en el mercado español sino en el mercado norteamericano.

33. Se puede deducir de estos FD del segundo Auto que la Audiencia una vez descartada la aplicación del foro de la sumisión expresa, valora los actos de competencia desleal como actos de responsabilidad extracontractual. Además, parece excluir la aplicación del Reglamento Bruselas I bis, porque el domicilio el demandado se encuentra en Estados Unidos. Lo único que nada dice que se aplique o bien el Reglamento Bruselas I bis, o bien la LOPJ. Directamente explica que se aplica el artículo $52.1 .^{\circ} 12^{\mathrm{a}}$ de la LEC. Es decir, valora y acepta la impugnación de la competencia judicial internacional mediante la declinatoria de la empresa norteamericana a través de la norma de la competencia territorial.

48 En la doctrina mercantilista se aprecia a la luz del análisis de la jurisprudencia en estos contratos y otros relacionados como el de agencia que la "cláusula de no competencia post contractual" no es generalmente considerado un deber nacido de la obligación contractual o del contrato entre las partes, v.gr., J. Alfaro ÁGuila ReAL, "Cláusulas de no competencia post-contractual, cláusulas penales, inducción a la infracción contractual y Derecho de la Competencia (I-IV)", 2011, disponible en: http:// derechomercantilespana.blogspot.com.es/2011/11/clausulas-de-no-competencia.html; F. MARCos, "Contratos con referencias a competidores (CRC): referencias contractuales a terceros y restricciones a la competencia”, Working Paper IE Law School, AJ8-253, 2020; A. SUÑol LuCEA, "Incumplimiento de la prohibición de competencia y competencia desleal", disponible en: https://almacendederecho.org/incumplimiento-de-la-prohibicion-de-no-competencia-y-competencia-desleal; desde la visión ius privatista, en los mismos contratos de distribución y concesión la calificación que puedan recibir en sede de competencia judicial internacional también ha sido muy controvertida pero por la falta de armonización material en la materia, A. CEBRIÁN SALVAT, "La concesión de venta y la competencia judicial internacional", Revista Castellano-Manchega de Ciencias sociales, $\mathrm{n}^{\circ} 19,2015$, pp. 197-210.

49 J. Alfaro Águila Real "Incumplimiento de un pacto de no competencia en un contrato de compraventa de empresa: no es competencia desleal", Derecho mercantil, 2011, disponible en: http://derechomercantilespana.blogspot.com.es/2011/09/ incumplimiento-de-un-pacto-de-no.html. 
34. La solución correcta hubiese sido aplicar primero el artículo 22 quinquies b de la LOPJ y de forma posterior el artículo 52.1. ${ }^{\circ} 12^{\mathrm{a}}$ de la LEC. Huelga decir que si hubiera sido de aplicación el artículo 7 apartado $2^{\circ}$ del Reglamento Bruselas $I$ bis, también de forma posterior se tendrían que haber aplicado el artículo 52.1. ${ }^{\circ} 2^{\mathrm{a}} \mathrm{LEC}^{50}$. Con independencia de si realmente luego los tribunales españoles hubieran tenido o no competencia en base a estos foros. Sólo se tiene a bien explicar, una omisión en el Auto del segundo procedimiento. La solución de aplicar el foro del sistema autónomo es porque no existen criterios de conexión para poder activar el foro especial por razón de la materia en alternancia con el foro general del domicilio del demandado del Reglamento Bruselas I bis.

35. De acuerdo al foro especial relativo a la obligación de tipo extracontractual de la LOPJ, -el artículo 22 quinquies b-, conocerán los tribunales españoles si el hecho dañoso se ha producido en territorio español (forum loci damni) ${ }^{51}$. El foro es cierto que no especifica, tal y como está redactado si también cupiese la posibilidad de entender en esta redacción el forum loci delicti commissi, como hace el artículo 7 apartado $2^{\circ}$ del Reglamento Bruselas I $b i s^{52}$. La diferencia tiene sentido desde la teoría y principios de estos foros ${ }^{53}$. Los establecidos por el legislador del Estado miembro en su derecho interno son atributivos. Los establecidos por el legislador europeo son distributivos, como bien se conoce ${ }^{54}$.

El foro del artículo 22 quinquies letra $\mathrm{b}$ es el destinado a determinar la competencia judicial internacional en materia de actos de competencia desleal, porque su caracterización clásica en el DIPr europeo y español es de obligación de tipo extracontractual, en defecto de no poder entenderse incluidos estos actos en la redacción de la cláusula de sumisión expresa o como una obligación nacida de la relación contractual entre los profesionales ${ }^{55}$.

Esta presunción se realiza desde estas líneas en cuanto parece desprenderse tal y como se aplica el artículo 52.1.12 de la LEC, que se pudo calificar la obligación que unía a las partes como extracontractual, como una contravención de un deber general de conducta en el mercado y no nacida de la obligación contractual en base al contrato de distribución en exclusiva que unió a las partes ${ }^{56}$, en cuanto la AP de Zaragoza rechaza que ya existiese ningún contrato entre ambas por haber sido resuelto.

\section{Disonancias cognitivas: la solución de la norma de competencia territorial en materia de com- petencia desleal y la solución de la norma de competencia judicial internacional}

36. El artículo 52.1.12 LEC contiene varios criterios para determinar la competencia territorial de los tribunales españoles una vez tienen atribuida la competencia judicial internacional. La redacción

${ }^{50}$ N. DíAz MÉndeZ, "La competencia territorial en los juicios en materia de competencia desleal”, La Ley, n², 1993, pp. 980-982; S. Barona Vilar, Competencia desleal (Doctrina y jurisprudencia), $2^{\mathrm{a}}$ ed., Tirant lo Blanch 1999; ID., Competencia desleal: Tutela jurisdiccional (especialmente proceso civil y extra-jurisdiccional) Doctrina, legislación y jurisprudencia, t.I y t.II, Tirant Lo Blanch, 2008; P. Rodríguez Mateos, “Competencia desleal”, en J. C. Fernández Rozas (Coord.), Derecho del Comercio internacional, Eurolex, 1996, pp. 169-189; R. ARENAS GARCíA, "Competencia territorial y competencia judicial internacional en el marco de la competencia desleal”, Derecho de los negocios, vol. 10, no. 103, 1999, pp. 16-23.

${ }^{51}$ Artículo 22 quinquies LOPJ, letra b: "en materia de obligaciones contractuales, cuando el hecho dañoso se haya producido en territorio español".

${ }^{52}$ Artículo 7 apartado $2^{\circ}$ del Reglamento Bruselas I bis: "en materia delictual o cuasi-delictual, ante el órgano jurisdiccional del lugar donde se haya producido o pueda producirse el hecho dañoso."Y según la consolidada jurisprudencia del TJUE sobre este foro que permite su aplicación en ilícitos ubicuos (producidos en dos lugares diferentes) o multilaterales (producidos en varios lugares de forma simultánea) desde la STJUE, as. Mines de Potasse, C-21/76 de 1 de octubre de 2002 (ECLI:EU:C:1976:166), y STJCE, as. Shevill, C-68/93, de 7 de marzo de 1995 (ECLI:EU:C:1995:61) para ilícitos de tipo multilateral.

${ }^{53}$ En ambos rige el "principio de proximidad "entre el lugar del hecho dañoso y el lugar donde se ha cometido el hecho causal y los tribunales. No obstante, desde la diferenciación de ser foros diseñados por un legislador nacional que sólo pueden atribuir competencia judicial internacional a sus tribunales. Y los internacionales-europeos que deben distribuirla entre los tribunales de varios Estados miembros, A. EsPinIella MenÉNDEZ, "Competencia judicial internacional...", loc.cit,,pp.285 y ss

${ }^{54}$ F.J. Garcimartín AlFérez \& M. Virgós Soriano, Derecho procesal civil internacional. Litigación internacional, Civitas,

2007; J.C. Fernández Rozas \& S. SÁnchez Lorenzo, Derecho internacional privado, 7aaed., Civitas, 2013, pp. 73 y ss.

55 Vid. supra Epígrafe I. Introducción.

56 Vid. supra apartado anterior. 
de este precepto no se encuentra en armonía con la redacción de estas normas de competencia judicial internacional, siendo la norma de competencia territorial mucho más exhaustiva en criterios de conexión para localizar un tribunal competente en litigios de competencia desleal en territorio español ${ }^{57}$.

37. Los criterios de este precepto son los siguientes por orden según el artículo son: el criterio del establecimiento del demandado y el domicilio o lugar de residencia (este último opera en caso de no conocer el domicilio) y sino lo tuviere en "territorio español" el lugar donde se cometió el acto comercial desleal (que viene siendo el equivalente al forum delicti commissi en las normas de competencia judicial internacional) o donde se produzcan los efectos del acto comercial (que viene siendo el equivalente al forum loci damni) siempre y cuando se produzcan en territorio español. Pero, ¿en base a qué efectos en el mercado? ¿concuerda con el criterio de conexión de la norma de competencia judicial internacional, esto es, el mercado afectado? ¿cómo se determinan estos efectos en el mercado?

38. Haría falta añadir que los efectos sustanciales se refieren a cuándo el acto de competencia desleal que se ha podido iniciar en el extranjero produce sus efectos en el mercado español (conocido como el criterio de minimis). También válido para los litigios en donde se sustancian infracciones privadas del Derecho antitrust ${ }^{58}$.

El criterio de minimis entiende que los actos de competencia desleal, para poder ser conocidos por el tribunal del lugar donde se han producido los efectos, deben haber causado un daño directo y sustancial en ese mercado que debe haber sido "afectado". No incluye el conocimiento de los daños indirectos. Con ello, lo que se limita es el uso abusivo de estos foros, conocido como bad forum shopping o forum shopping indiscriminado, cuando se aplica este foro de la obligación de tipo extracontractual para estos litigios ${ }^{59}$.

39. No obstante, y aunque este no parecía ser el argumento de relevancia en este auto en particular de la AAP de Zaragoza del segundo procedimiento (2020) si cabe recordar que la consideración de los "efectos" en el mercado no es muy clara en la norma, teniendo en cuenta que el criterio clásico de la disciplina, -reconocido en sede de competencia judicial internacional en la jurisprudencia y Doctrina-, más que el de los efectos, se constituye como el del "mercado afectado" para los litigios de competencia desleal. Al abrigo de esta evolución como ilícito de mercado, como un cuerpo de normas ordenador de las conductas en los mercados. Los efectos pueden ser provocados por cualquier acto, por ello es importante determinar en dónde y qué tipo de efectos ${ }^{60}$. En litigios del Derecho de la competencia, incluyendo

${ }^{57}$ Aunque a niveles diferentes, tampoco se encuentra en armonía con la solución ofrecida en sede de ley aplicable que ya reconoce el criterio del mercado afectado como el adecuado para los litigios transfronterizos de competencia desleal, vid. Artículo 6 Reglamento Roma II, apartados $1^{\circ}$ y $2^{\circ}$ y Considerando 21 Roma II..

${ }_{58}$ Para los litigios en materia de Derecho antitrust, el criterio adecuado consagrado es el criterio del "mercado relevante", aparte de los efectos sustanciales y directos en el mismo. Para los litigios de competencia desleal es el criterio diferenciado del "mercado afectado".

${ }^{59}$ Inter alia, M. Virgós Soriano, El comercio internacional y el nuevo..., loc.cit.; C.Otero García CASTRILlón, "El alcance extraterritorial del...", loc.cit,; T. BAUERMANn, Der Anknüpfungsgegenstand im europäischen Internationalen Lauterkeitsrecht, Mohr Siebeck, 2015; T.W.DORNIS, Trademark and Unfair Competition Conflicts-Historial-Comparative, Doctrinal and Economic perspectives, Cambridge University Press, 2017; P. MANKOWSKI, "Der europäische Gerccihtasstand des Tatortes aus Art. 5 Nr. 3 EuGVVO bei Schadensersatzklagen bei Kartelldelikten”, WuW, n9, 2012, pp. 797-807.

${ }^{60}$ A. L. Calvo Caravaca \& J. Carrascosa González, Derecho Internacional Privado, Vol.I, op.cit., pp. 131-133 y pp 348350; ID., "Competencia judicial internacional y competencia desleal transfronteriza a la luz del caso REPSOL v. YPF", Rivista internationale de Diritto internationale e procesale, ${ }^{\circ} 1$, vol. 4, 2014, pp. 4-30; P. MANKowski, "Special Jurisdiction", en U. Magnus \& P. Mankowski, Brussels I Regulation (European Commentaries on Private International Law), Sellier, 2007, pp. 211-217, esp. p. 212; R. Hitty, "The Law Against Unfair Competition...”, loc.cit., en Hitty/ Henning Bodewig, Law Against Unfair Competition..., op.cit., pp. 13-14; R. ARENAS GARCíA, "Competencia judicial internacional y demandas por competencia desleal. El retorno del Imperialismo jurisdiccional”, AEDIPr, t. XII, (2014), pp. 1001-1009; A. Font SegurA, La protección internacional del secreto empresarial..., op.cit., de forma diferente pero un supuesto de competencia desleal transfronteriza relevante en la jurisprudencia española, el Auto del Juzgado de lo Mercantil n ${ }^{\circ}$, de Madrid n²3/2013, de 5 de julio de 2013 (ECLI:ES:JMM:2013:23:A) (asunto Repsol vs. IRF Argentina); P. Orejudo Prieto De Los Mozos, “Jurisprudencia española y comunitaria de Derecho internacional privado. Derecho del comercio internacional. Competencia desleal. Propiedades inmateriales. Delimitación competencia desleal/propiedades inmateriales. Protección del Derecho unionista. Aplicación de la ley de 
competencia desleal y aplicación privada del Derecho antitrust, suelen ser los efectos económicos perjudiciales para el mercado, los competidores y / o los consumidores, dependiendo del ilícito concurrencial desleal que se dilucide en sede judicial.

40. De otra parte, en el apartado anterior se hace referencia a que la AP de Zaragoza ${ }^{61}$, en el AAP de Zaragoza (2020) no queda bien delimitada ni la competencia judicial internacional ni la competencia territorial según el FD $1^{\circ}$. Llegando al FD $3^{\circ}$ del AAP en donde se lee que el Reglamento Bruselas I bis reenvía a las normas procesales de competencia territorial en su artículo 6, pero no a las de competencia judicial internacional si el demandado no se encuentra domiciliado en un Estado miembro ${ }^{62}$. En este particular, cabe recordar que el artículo 6 se remite a las normas procesales incluyendo las de competencia judicial internacional si las hubiere en ese ordenamiento jurídico del Estado miembro, en cuestión. No únicamente a las normas de corte territorial, sino a la lex fori en su conjunto. Cumpliendo ambas normas a nivel de Derecho procesal civil internacional diferente función, en los ordenamientos jurídicos que, como el español, cuentan con ambas ${ }^{63}$. De hecho, es necesario también que los tribunales, contando con normas de competencia judicial internacional califiquen antes de aplicar las normas de corte territorial, la obligación que sirve de base a la demanda desde este nivel ${ }^{64}$.

41. Con la lógica que el Derecho procesal civil internacional español es un sistema dualista. A diferencia de aquellos sistemas como el alemán, que son monistas, en los que los foros de competencia territorial sí pueden hacer la función de atribuir la competencia judicial internacional a la vez que la competencia territorial, en defecto de normas de competencia judicial internacional concretas.

En el ordenamiento jurídico español, en el caso que las normas de competencia judicial internacional no alcancen a cubrir los supuestos transfronterizos, podrían usarse la norma de competencia territorial específicas. Sin embargo, en supuestos de competencia desleal, se observa que no sería necesario acudir a esta técnica acogida por la tesis alemana, en cuanto el foro de la competencia territorial es bastante prolijo en criterios de conexión ${ }^{65}$. Ahora bien, es cierto que a veces si los tribunales no tienen atribuida la competencia judicial internacional por la misma norma, no significa que la norma de competencia territorial no les otorgue competencia (al menos, en este nivel). Siendo al revés más difícil en sistemas dualistas ${ }^{66}$.

\section{Conclusiones}

42. Primera: Sobre el alcance de las cláusulas de sumisión expresa a los actos de competencia desleal.- Las cláusulas de sumisión expresa basadas en el principio de la autonomía de la voluntad de las partes y en el ejercicio de esta autonomía de la voluntad, aún con los límites que conlleva en el respeto del orden público, pueden alcanzar en su redacción el conocimiento de los actos o prácticas comerciales

competencia desleal: Mercado español afectado. Legitimación activa: Sentencia de la Audiencia provincial de Madrid (sección $14^{\mathrm{a}}$ ) de 3 de septiembre de 2003", REDI, vol. 56, nº 1, 2004, pp. 408-417.

${ }^{61}$ Ibidem.

${ }^{62} \mathrm{FD} 3^{\circ}$ in fine: "Por tanto, tratándose de personas domiciliadas fuera del ámbito comunitario, la norma reenvía al derecho interno, o sea, el artículo 52. ${ }^{\circ} .12$ LEC o el tratado correspondiente" (sic.); por todos, R. ARENAS GARCÍA, "Falta e impugnación de la competencia judicial internacional en la LEC (2000)", $A E D I P r$, t. I, (2001), pp. 155-199

${ }^{63}$ No siendo la primera vez que sucede, justificar o no (como en este caso) la competencia judicial internacional de los tribunales españoles en base a la norma de competencia territorial o incluso en base al criterio establecido en la norma de conflicto para los asuntos de competencia desleal transfronteriza, A. FonT SEGURA, "Infructuoso intento de justificar la competencia y la jurisdicción española con base en el art. 4 de la Ley de competencia desleal”, $A E D I P r$, t. V., 2005, pp. 676-680.

${ }^{64}$ A-L. Calvo Caravaca \& J. Carrascosa González, Derecho Internacional ..., vol. I.., , esp. pp. 170-171.Y no en base a las pretensiones de las partes.

65 Ibid., (Calvo Caravaca \&Carrascosa González), p. 349; J.C. Fernández Rozas \& S. Sánchez Lorenzo, Derecho internacional ..., op.cit., p. 104. Los principios que informan los foros de competencia judicial internacional nada tienen que ver con los criterios que informan la competencia territorial.

${ }^{66}$ R. Arenas García, "Falta e impugnación de la competencia judicial internacional en ...", loc.cit. 
desleales bien sean nacidas de "deberes" de tipo contractual (relaciones comerciales) u obligaciones de tipo extracontractual que han surgido como consecuencia de las anteriores.

43. Dependerá de la redacción y el acuerdo entre las partes, atendiendo a la autonomía que tienen frente al resto de cláusulas contractuales. Con ello, estas cláusulas pueden subsistir por el principio de separabilidad a la misma nulidad del contrato. Debiendo ser el tribunal que tiene competencia judicial internacional atribuida por la cláusula, el que valore si la misma debe subsistir y a la luz del artículo 25 Reglamento Bruselas I bis (que era en este supuesto de hecho, el foro adecuado para analizar la validez y alcance de la cláusula en el caso de Autos.

44. Si la cláusula resulta ser válida incluso después de resuelto el contrato en donde está incluida, y en la misma se somete todo litigio o controversia a los tribunales de un Estado (sin especificar la naturaleza del mismo), al no activar el foro especial de la responsabilidad extracontractual que es el que de forma clásica se activa para los supuestos de competencia desleal transfronteriza por sus características. Sería desplazado por la autonomía de la voluntad de las partes. En este foro de la sumisión expresa, el criterio del mercado afectado y / o el de los efectos no opera para determinar el alcance de los daños en el presunto mercado afectado, siendo el criterio de conexión que se usa para el foro especial por razón de la materia de la responsabilidad extracontractual. Ni siquiera se aplica para el otro foro alternativo a este, el foro general del domicilio del demandado.

45. Quizás, una solución para evitar problemas de determinación de la competencia judicial y la competencia territorial en estos casos, podría ser incluir en la redacción de la cláusula de sumisión expresa una referencia a la competencia territorial, aparte de la competencia judicial internacional, que incluya aspectos relativos a los mercados que podrían verse afectados por determinados actos surgidos o en relación con las relaciones de tipo comercial entre las partes en redes de distribución, y análogas.

46. Segunda: Sobre el ámbito material de la Convención de la Haya de 2005 y la competencia desleal.- La Convención de la Haya de 2005 en el caso de haberse podido aplicar, si incluye en su ámbito material los actos y prácticas comerciales desleales, para que los tribunales de los Estados en los que están en vigor la Convención, analicen la validez y el alcance de las cláusulas de sumisión expresa.

47. En este caso, podrían haber conocido los tribunales de Zaragoza, siempre y cuando también la redacción de la cláusula hubiera sido tan amplia para entender estos actos incluidos (que aparentemente lo era).

Si hubiese existido un pacto de no competencia post contractual entre las partes (que se desconoce) y se hubiese delimitado que lo que realmente se demandaba era una infracción al Derecho de la libre competencia, pero nacida de la relación contractual, también se hubiese entendido incluida dicha infracción en el alcance de dicha cláusula y de la Convención de la Haya de 2005. A la vista que para estos supuestos nos encontraríamos ante infracciones del Derecho de la competencia que nacen de determinado tipo de obligaciones/relaciones contractuales que afectan a derechos de exclusiva. No de infracciones directas a las normas del Derecho de la libre competencia o antitrust.

48. Tercera: Sobre la norma de competencia judicial y la norma especial de competencia territorial para litigios de competencia desleal transfronteriza.- El sistema procesal civil internacional español en es un sistema dualista. Esto explica que para poder determinar cada una de estas competencias deba acudirse a las diferentes normas establecidas para cada uno de estos niveles procesales. En particular, en materias como la competencia desleal que tienen criterios de conexión claros reconocidos en ambos niveles procesales. Y para calificar de forma previa la obligación que sirve de base a la demanda primero mediante los foros de competencia judicial internacional.

49. La aplicación del foro del artículo 22 quinquies b de la LOPJ se activa si el demandado no tiene su domicilio en un Estado miembro. Con independencia de la solución que ofrece el artículo 
52.1.12 $2^{\mathrm{a}}$ de la LEC que es una norma de competencia territorial que, los tribunales españoles deberán usar para delimitar dicha competencia una vez entendida que sí tienen atribuida la competencia judicial internacional ora sea por el Reglamento Bruselas I bis, u otros Convenios internacionales en la materia o el foro de la obligación de tipo extracontractual de la LOPJ. En defecto que no operen otros foros, como el de la sumisión expresa.

50. El criterio de los efectos sólo establecido de forma explícita en el foro de competencia territorial, debe ser entendido como el criterio del mercado afectado que incluye en si mismo este criterio de los efectos, cuando previamente se haya aplicado el foro adecuado de competencia judicial internacional a los asuntos de competencia desleal transfronteriza si son calificados en este nivel procesal como una obligación extracontractual: el artículo 22 quinquies b de la LOPJ.

Hasta que no se produzca un cambio legislativo en la redacción de la norma de competencia judicial internacional de las obligaciones de tipo extracontractual del sistema procesal civil internacional español, se debe entender que tanto el lugar del hecho dañoso como el lugar donde se ha cometido o comenzó el hecho dañoso, es el mercado español. Sólo el mercado español. Primero: según la estructura de norma atributiva de la competencia judicial internacional que tiene la española, a diferencia de la norma del legislador europeo y el internacional en Convenios internacionales de competencia judicial internacional. Segundo: a falta de no tener tampoco una jurisprudencia consolidada sobre la debida interpretación del artículo 22 quinquies b de la LOPJ en litigios de competencia desleal transfronteriza, que alcance también el lugar desde donde se cometió o empezó el hecho dañoso (forum delicti commissi) se propone una interpretación extensiva de su letra (pero sólo desde el parecer de estas líneas). Entendiendo también que el mercado de ataque debe ser el español, dado que dado que del lado contrario no tendrían competencia judicial internacional los tribunales españoles.

51. Para finalizar, aunque los efectos se hubieran desplegado en el mercado norteamericano, cabe presumir que podrían haberse comenzado en el mercado español, o incluso haber desplegado efectos también en el mercado español, siendo ambos mercados los afectados-lugares del daño, directo y sustancial. En este supuesto, los tribunales de Zaragoza si hubiesen tenido competencia judicial internacional atrubuida por el foro de la responsabilidad extracontractual de la LOPJ, y el de competencia territorial, para conocer de estos presuntos actos de competencia desleal, en base a este análisis realizado. 